\title{
Is Mass Media Exposure Associated with Tobacco and Alcohol Consumption Behaviour: Evidence from India
}

\section{Rashmi}

International Institute for Population Sciences

Ronak Paul ( $\square$ greenophenn@gmail.com )

International Institute for Population Sciences

Bhavna Majumdar

International Institute for Population Sciences

\section{Research Article}

Keywords: Smoking, Alcohol consumption, Lifestyle, Heterogeneity, India

Posted Date: September 2nd, 2020

DOI: https://doi.org/10.21203/rs.3.rs-69298/v1

License: (c) (i) This work is licensed under a Creative Commons Attribution 4.0 International License.

Read Full License 


\section{Abstract}

Tobacco and alcohol consumption are one of the leading lifestyle-related causes of avoidable mortality worldwide. India is the second-largest consumer of tobacco globally after China. The pattern of tobacco smoking, tobacco chewing and alcohol consumption varies across the states and regions of India. Past literature has provided varying evidence regarding the influence of media on the tobacco and alcohol consumption behaviour of Indian people in specific regions and/or specific age brackets. The current study examined the association between media exposure in households and the individual consumption behaviour of tobacco and alcohol in the Indian population while simultaneously accounting for unobserved heterogeneity at the state level. The analysis was performed separately for both rounds of India Human Development Survey (IHDS) cross-sectional datasets. Multivariable standard logit regression models and random-intercept logit regression models were used to fulfil the study objectives. The study showed that exposure to radio and television media in households was associated with a high risk of smoking tobacco and drinking alcohol in both rounds of IHDS. However, exposure to newspaper media in households translated to a lower risk of tobacco and alcohol consumption in both rounds. People aged 20-59 years were highly likely to consume tobacco or alcohol compared to younger individuals in both rounds of data. Additionally, females are more likely to chew tobacco compared to their male counterparts. The study also provides evidence of the presence of a high level of heterogeneity in the risk of smoking tobacco, chewing tobacco and drinking alcohol across the states of India. The findings of the study highlight the need for devising effective policies that curb the role of radio and television mass media as a promotional medium for tobacco and alcohol consumption among the Indian population.

\section{Introduction}

Over the years, media had played an influential role in every person's life. Exposure to mass media has not only brought information among people but has also shaped perception in people's minds through the information provided by them. The role of different media sources such as print media, broadcast media and others cannot be denied, as they have served as a means of communication to their audiences. The media holds the power to both promote and control any kind of behaviour among their audiences. Thus, the role of media can be seen as both pro and anti-agents of knowledge related to human health (National Cancer Institute, 2008). Several studies had linked media with alcohol and tobacco consumption among the population. Some literature had brought forward the influence of media towards promoting the consumption (Wakefield et al., 2003; Anderson et al., 2009; Nunez-Smith et al., 2010) while some have shown the discouraging role of media with all forms of tobacco and alcohol consumption (Holak \& Reddy, 1986; Young et al., 2018; National Cancer Institute, 2008, pp. 357-423).

Tobacco and alcohol use are the biggest preventable cause of death across the world. According to the World Health Organisation (WHO), almost 3 million deaths were reported among people who consume alcohol in 2016 (Hammer et al., 2018). Further, 155 million adolescents worldwide, aged 15-19 years were current drinkers in 2016 (Hammer et al., 2018). In developed countries, despite several pieces of 
evidence about the harmful impact of consuming these substances, nearly 4,000 young people initiate their first cigarette each day (National Cancer Institute, 2008). India is the second-largest tobacco consumer of the world (John et al., 2009) however the statistics from the second round data of Global Adult Tobacco Survey (GATS), had shown that almost $92.4 \%$ of people believe that smoking leads to serious illnesses among people (Ministry of Health and Family Welfare Government of India, 2017). The report of the round 4 of National Family Health Survey (NFHS) of India revealed that almost $30 \%$ and $45 \%$ of men consume alcohol and different forms of tobacco respectively (Factsheet, 2017). Past literature had also shown that alcohol consumption not only affected the health of men but also adversely affects the health of women and children. As alcohol consumption can lead to negative consequences on a newborn child (Schoeps et al., 2018), the association is also seen with the risk of unintended pregnancy and lifelong disorder in children like foetal alcohol spectrum disorders (Chudley et al., 2005; Connery et al., 2014). In India, $38.7 \%$ and $30.2 \%$ of adults were exposed to passive smoking at home and workplace respectively (Ministry of Health and Family Welfare Government of India, 2017). The role of media behind such consumption behaviour can be influential, both negatively and positively.

Different research evidence had brought forward the consumption pattern of alcohol and tobacco in developed and developing countries (Sinha et al.,2011; Singh \& Ladusingh, 2014; Anand \& Roy, 2016). Some studies show that the consumption of alcohol and tobacco is most common among men than women in India (Anand \& Roy, 2016; Mohan et al., 2018). Different traditions and social norms also promote these kinds of consumptions especially in rural areas and people usually prefer traditional drinks over the modern ones (Chakrabarti et al., 2012). Level of education and occupational status were prominent determinants of alcohol and tobacco in the study of Anand \& Roy (2016) They found that men working in the informal sectors were more prone to these products. In the study by Singh \& Ladusingh (2014) tobacco use was also found to be significantly varying among the states and regions of India. Alcohol trade is also an important source of revenue in India, where non-commercial production of alcohol is the primary livelihood of women from Assam and Sikkim (Chakrabarti et al., 2012). Smoking and drinking alcohol is still a taboo among women in certain parts of the country but chewing tobacco is common among women due to their acceptability in society, ease of availability and inexpensiveness (Gupta et al.,2016; Sauvaget et al., 2008). Thankappan \& Thresia, (2007) had shown that ban on smoking in the public places of India had resulted in an increment in smokeless tobacco consumption in India. Further, the marketing of these products is done by promoting them as an inalienable part of the consumer's lifestyle. Direct and indirect advertisement of these products through the media influences the consumers and encourages them to use it. According to the study by Mathivanan et al., (2015), children are the vulnerable section of society when it comes to media influence. Children are easily influenced by mass media exposure because of their inability to differentiate between the reality and the fantasy world created through different mass media messages. The same study had also portrayed the role of peer influence behind the consumption of tobacco and alcohol by Indian children. However, the media had also played a supportive role towards reducing smoking and tobacco consumption rate. Different campaigns are promoted through media sources against the pro-tobacco and pro-alcohol marketing strategies of companies (Young et al., 2018; National Cancer Institute, 2008). Viswanath et al., (2010) had 
shown in their study that exposure to newspapers is a reducing factor behind the rate of tobacco consumption. However, the same study highlighted that exposure to television was associated with a higher prevalence of smoking among men and an increase in the prevalence of chewing tobacco among both men and women in India.

Previous research has provided evidence that media plays an important role in shaping the attitudes of individuals towards the consumption of alcohol and tobacco (McCool et al., 2014; National Cancer Institute, 2008). However, majority of these studies were based on developed countries. There is a death of research evidence, which documents the role of mass media behind tobacco and alcohol consumption behaviour in developing countries like India. Past research on the influence of media on the consumption behaviour of alcohol and tobacco has classified the impact into two categories_- positive impact and negative impact (National Cancer Institute, 2008; Viswanath et al., 2010). However, these studies focused on people from specific regions as well as from particular age brackets of India. The objective of the current study is to understand the role of media behind the tobacco and alcohol consumption behaviour of the Indian population across all regions and age groups. According to (National Cancer Institute, 2008) an extensive study of the role of media in control and promotion of different consumption behaviour among people, requires a multilevel modelling approach where the individual-level factors show how individual behaviour matters while an upper level helps to understand how the upper level of media structure influences them. Thus, the current study examines the association of media exposure in household with tobacco and alcohol use among individuals simultaneously accounting for the unobserved heterogeneity at the state level.

\section{Methods}

\section{Data}

This study used the first and second round of India Human Development Survey (IHDS). IHDS round I is a nationally representative, a multi-topic survey of 41,554 households in 382 districts, 1503 villages, and 971 urban neighbourhoods of India conducted during 2004-05 (Desai et al., 2008). The IHDS round II is also a multi-topic panel survey of 42,152 households in 384 districts, 1420 villages, and 1042 urban neighbourhoods of India conducted during 2011-12 (Desai \& Vanneman, 2015). Both rounds of IHDS have been conducted in all states and union territories of India (except for the two union territories of Andaman and Nicobar Islands and Lakshadweep) using a multi-stage stratified random sampling. For details regarding the IHDS sampling design please refer to (Desai et al., 2010).

During the first and second rounds of IHDS, data for tobacco and alcohol consumption were collected from 33116 and 34090 individuals respectively. These subsets of observations from the original crosssectional datasets were used respectively from both rounds for analysis. Any observations with missing information regarding tobacco and alcohol consumption were retained for analysis. The association between media exposure and tobacco and alcohol consumption was examined separately for both rounds using the same set of the outcome, explanatory, and control variables. 


\section{Outcome variables}

During the first round of IHDS, interviewers collected information about whether an individual "smokes cigarettes, bidis or hukkah", "chews tobacco" and "drinks alcohol". The answers were coded into three categories-"never", "sometimes", "daily". For analytical purpose the information was converted into binary nature-persons in "sometimes" or "daily" category were coded into "yes" and otherwise they were coded as "no". Thus, the three outcome variables used in the first round were-whether a person smokes tobacco (no, yes), whether a person chews tobacco (no, yes), and whether a person drinks alcohol (no, yes).

A similar procedure was used in the second round of IHDS too for the construction of outcome variables. In the second round, interviewers collected information about whether an individual "smokes cigarettes", "smokes bidis or hukkah", "chews tobacco" and "drinks alcohol". The information was coded into four categories-"never", "rarely", "sometimes", "daily". For analysis, the persons in "sometimes" or "daily" category were coded as "yes" and otherwise they were coded as "no". The variables "smoking cigarettes" and "smoking bidis or hukkah" were combined into a single variable indicating whether a person smokes tobacco (yes, no). Persons who smoked either or both cigarettes, bidis or hukkah were coded as "yes"; otherwise they were coded as "no". The other two outcome variables in the analysis of second-round data are-whether the person chews tobacco (no, yes) and whether the person drinks alcohol (no, yes).

\section{Explanatory variables}

The indicators of mass media exposure are used as the explanatory variables in both rounds of datasets. During the first round, interviewers asked respondents that how often do people in the household "listen to radio", "read the newspaper" and "watch television (TV)". The three questions were asked separately for men, women, and children of the household, and answers were recorded under three categories -"never", "sometimes", "daily". This information was combined to construct three binary variableswhether anyone in the household listens to radio (no, yes), whether anyone in the household reads the newspaper (no, yes) and whether anyone in the household watches TV (no, yes). This study constructed variable, the households in "sometimes" and "daily" category in the original variable as "yes"; otherwise, they were recoded to "no".

A similar procedure of recording was used for the mass media exposure-related variables in the second round of IHDS. Interviewers in the second round asked respondents how often do people in the household "listen to radio", "read the newspaper" and "watch TV". Again, the three questions were asked separately for men, women, and children in the household, and answers were recorded under three categories -"never", "sometimes", "daily". The information was combined to construct three binary variableswhether anyone in the household listens to radio (no, yes), reads the newspaper (no, yes), and watches TV (no, yes). Households in "sometimes" and "daily" category in the original variable were recoded to "yes" and otherwise they were recoded to "no" in the constructed variable. 


\section{Control variables}

Based on previous research, several factors that affect the media exposure, tobacco, and alcohol consumption behaviour of individuals were identified. These factors were individual-level demographic characteristics, household socio-economic characteristics, and state-level relevant characteristics. Accordingly, the following control variables were included for analysis-age category of the individual (grouped in interval of 10 years); sex of individual (male, female); level of education of individual (no formal schooling, standard 1-5, standard 6-10, standard $>10$ ); current working status of individual (not working, working); current marital status of individual (unmarried, married); highest educational level of an adult male aged more than 21 years in the household (no formal schooling, standard 1-5, standard 6-10 and standard > 10); highest educational level of an adult female aged more than 21 years in the household (no formal schooling, standard 1-5, standard 6-10 and standard $>10$ ); wealth quintile of household (poorest, poor, middle, rich and richest); caste of the household head (other backward class (OBC), scheduled castes (SC), scheduled tribes (ST), others); religion of the household head (hindu, muslim, others); place of residence (rural, urban); region (central, northern, southern, western, eastern, north-eastern).

Very few of the control variables had observations with missing information. In the first round of IHDS, there were 589 and 699 missing cases in the highest educational level of household female adult and household male adult variables respectively out of 33116 cases. In the second round of IHDS, there were 45, 523 and 707 missing cases in the caste of household head, highest educational level of household female adult and highest educational level of household male adult variables respectively out of 34090 cases. The observations with missing cases for a particular variable were either recoded as " 0 " or to the "others" category as appropriate. Since the number of individuals with missing information were small relative to the overall sample size, this recoding will not bias the analysis done in this paper.

\section{Analytical Methods}

In the beginning, the current study shows the overall distribution of individuals as well as the distribution of individuals who smoke tobacco, chew tobacco and drink alcohol respectively across the relevant demographic, socio-economic and state-level variables used in the dataset. Then the study provided evidence of the presence of unobserved state-level heterogeneity in the data using random intercept logit models with individuals at the first level and the state an individual belongs to at the second level. In both rounds of IHDS, individuals have been grouped under 28 states and 5 union territories and each of such entity (states as well as the union territories) has been considered as a separate state for analysis. There were no individuals who belonged to multiple states and there were no states without any individuals in them. Further, the study provides evidence for the association between mass media exposure in households and tobacco and alcohol consumption behaviour in individuals using multivariable standard logit regression models and random intercept logit regression models, before and after controlling for 
state-level heterogeneity respectively. Logit regression models were used as the dependent variables are binary.

To give evidence of unobserved state-level heterogeneity, the study estimated a null model (empty random intercept logit model with no explanatory and control variables) and a full model (random intercept logit model with all the explanatory and control variables) for each of the three indicators of tobacco and alcohol consumption. Clustering and heterogeneity in the random intercept logit models was measured using the intra-class correlation coefficient (ICC) and median odds ratio (MOR) respectively. The ICC is the ratio of variation in the risk of tobacco or alcohol consumption across the states (second level units) to the sum of the individual-level and state-level variation (Merlo et al., 2006). In the case of two-level random intercept logit regression models, the individual-level variation is fixed and the ICC is a function of only the state-level variance whose value lies within 0 and 1 . The higher the value of ICC the greater is the degree of clustering of observation within the state. The MOR gives the median of the ratio of the propensity of tobacco or alcohol consumption among all pairs of individuals belonging to high-risk and low-risk states (Merlo et al., 2006). The MOR too is a function of the state-level variance whose value is always greater than or equal to 1. A high value of MOR denotes a greater level of heterogeneity in the risk of tobacco or alcohol consumption across the states. To give evidence of the association between media exposure and tobacco and alcohol consumption behaviour this study estimated a standard logit regression model (model without controlling for unobserved heterogeneity) and random intercept logit model (model after controlling for unobserved heterogeneity) for each of the three indicators of tobacco and alcohol consumption. Association in the standard and random intercept logit regression models were shown using odds ratios. The odds ratio for standard logit regression models gives the likehood of tobacco or alcohol consumption among the individuals within media exposure compared to those individuals without media exposure after controlling the effect of the control variables (Cameron \& Trivedi, 2005). The interpretation for odds ratio is similar in the case of random intercept logit regression models except that they additionally control for the effect of unobserved state-level heterogeneity (Goldstein, 2011; Snijders \& Bosker, 2011).

All the above analytical procedures were followed separately for both rounds of the IHDS dataset. All statistical estimations were performed using the STATA software (StataCorp, 2013).

\section{Results}

\section{Sample characteristics}

Table- 1 shows the distribution of individuals who smoke tobacco, chew tobacco as well as drink alcohol in the first round of IHDS (2004-05). Overall, there were 33116 individuals out of which 19281, 19460 and 10292 persons smoked tobacco, chewed tobacco and drank alcohol respectively. $51.2 \%, 59.4 \%$ and $66.6 \%$ of the individuals who smoked tobacco belonged to households that listened to radio, does not read newspaper and watched TV respectively. Among the individuals who smoked tobacco, $94.5 \%$ were male, $41.3 \%$ have had no formal schooling, $56.8 \%$ were currently working, $88 \%$ were married and $80.7 \%$ 
lived in rural households. Similarly, among the individuals who chewed tobacco 52.3\%, 57\% and $67.3 \%$ belonged to household that listened to radio, does not read newspaper and watched TV respectively. Additionally, $22 \%, 43.2 \%, 50.8 \%, 83 \%$ and $82.2 \%$ of the individuals chewing tobacco were female, had no formal schooling at all, were currently working, were currently married and lived in lived in rural households respectively. Again, $50.8 \%, 57 \%$ and $70.1 \%$ of the individuals who drink alcohol belonged to households that does not listen to radio, does not read newspaper and watched TV respectively. Additionally, among the individuals who drink alcohol, $94 \%$ were male, $41.7 \%$ have had no formal schooling, $66.7 \%$ were currently working, $89.5 \%$ were currently married and $80.5 \%$ lived in rural households. In addition, more than $45 \%$ of the individuals who consume tobacco or alcohol are aged between 30 and 49 years. More than $50 \%$ of the individuals consuming tobacco belong to the eastern and central region of India. The eastern and southern region of India accounts for more than $50 \%$ of the individuals who consume alcohol.

Table-2 shows the distribution of individuals who consume tobacco and alcohol during the second round of IHDS (2011-12). Second round of IHDS interviewed 34090 respondents out of which 14688, 21085 and 9877 individuals smoked tobacco, chewed tobacco and drank alcohol respectively. Among the individuals who smoked tobacco $67.4 \%, 52.6 \%$ and $78.8 \%$ belonged to household that does not listen to radio, does not read newspaper and watched TV respectively. Additionally, 93.7\%, 40\%, 85.5\%, 87.3\% and $77.1 \%$ of the individuals smoking tobacco were male, had no formal schooling at all, were currently working, were currently married and lived in lived in rural households respectively. Similarly, $65 \%, 51.4 \%$ and $77.1 \%$ of the individuals who chewed tobacco belonged to households that does not listen to radio, does not read newspaper and watched TV respectively. Additionally, among the individuals who chewed tobacco, $20.7 \%$ were female, $39.5 \%$ have had no formal schooling, $76.9 \%$ were currently working, $80.9 \%$ were currently married and $77.6 \%$ lived in rural households respectively. Again, among the individuals who drink alcohol $70.1 \%, 52.5 \%$ and $77.4 \%$ belonged to household that does not listen to radio, does not read newspaper and watched TV respectively. Additionally, $96 \%, 37.3 \%, 90.1 \%, 88.7 \%$ and $74.9 \%$ of the individuals smoking tobacco were male, had no formal schooling at all, were currently working, were currently married and lived in lived in rural households respectively. In addition, more than $40 \%$ of the individuals who consume tobacco or alcohol are aged between 30 and 49 years. More than $50 \%$ of the individuals consuming tobacco belong to the eastern and central region of India. The eastern, central and southern region of India accounts for more than $74 \%$ of the individuals who consume alcohol.

\section{State-level heterogeneity and clustering}

Table-3 gives estimate of the state-level unobserved heterogeneity in the risk of tobacco and alcohol consumption and clustering of observations across states using the random intercept logit models used for analysis of the first round of IHDS data. In case of models with "individual smokes tobacco or not" as the outcome variable, the amount of clustering among individuals within the same state, denoted by ICC of the null model (with no explanatory and control variables) and full model (with all explanatory and control variables), is 0.259 and 0.172 respectively. Similarly, for models with "individual chews tobacco or 
not" as the outcome variable the ICC for null model 0.435 which decreases to 0.189 in the full model. Again, for models with "individual drinks alcohol or not" as the outcome variable the ICC for the null model and full model is 0.307 and 0.275 respectively. The analysis shows that the observations for individuals who consume tobacco or alcohol are clustered within the same states. The MOR of the propensity of smoking tobacco, chewing tobacco and drinking alcohol is $2.78,4.56$ and 3.16 times higher for individuals belonging to high-risk states compared to the individuals belonging to low-risk states in the null models. The MOR decreases to 2.20, 2.31 and 2.90 in the full models for smoking tobacco, chewing tobacco and drinking alcohol respectively. The analysis shows that the MOR for all the models is greater than 2.00 and hence there is heterogeneity in the risk of tobacco and alcohol consumption of individuals across the states.

Table- 4 gives evidence of the state-level heterogeneity in the risk of tobacco and alcohol consumption and clustering of observations across states in the second round of IHDS data. The ICC for null models of smoking tobacco, chewing tobacco and drinking alcohol are $0.257,0.355$ and 0.271 respectively. For full models of smoking tobacco and chewing tobacco, the ICC decreases to 0.184 and 0.287 respectively whereas, the ICC increases to 0.289 for the model with drinking alcohol as the outcome variable. Similar to the first round, the observations for individuals who consume tobacco or alcohol are clustered within the same states in the second round of IHDS. The MOR of the propensity of smoking tobacco, chewing tobacco and drinking alcohol more than 2 times higher for individuals belonging to high-risk states compared to the individuals belonging to low-risk states in the all the models. Hence, there is heterogeneity in the risk of tobacco and alcohol consumption of individuals across the states.

\section{Association of mass media exposure and tobacco and alcohol consumption using state level heterogeneity}

Table -5 shows the association between different modes of mass media exposure in household and tobacco and alcohol consumption among individuals in the first round of IHDS. In the models that did not control for unobserved state-level heterogeneity, the odds of smoking tobacco is 1.07 times higher (standard error (SE: 0.029; p-value < 0.05) and 0.91 times lower (SE: 0.031; p-value < 0.01) for individuals who belong to households where the household members listen to radio and read newspaper respectively. Similarly, the odds of chewing tobacco is 1.09 times higher (SE: $0.030 ; p$-value < 0.01), 1.18 times higher (SE: 0.041; p-value < 0.01) and 0.93 times lower (SE: 0.031 ; p-value < 0.01) for individuals from households that listen to radio, read newspaper and watch TV respectively for models without unobserved state-level heterogeneity. Again, the odds of drinking alcohol is 1.06 times higher (SE: 0.029; p-value < 0.05), 1.10 times higher (SE: 0.038; $p$-value < 0.01) and 1.13 times higher (SE: 0.038; $p$-value < 0.01 ) for individuals from households that listen to radio, read newspaper and watch TV respectively for models without unobserved state-level heterogeneity. The pattern of association between the outcome and explanatory variables remains similar for models that control for unobserved state-level heterogeneity. Individuals have 1.08 times higher (SE: 0.032; $p$-value < 0.01 ) and 0.92 times lower (SE: 0.028; $p$-value $<0.01$ ) chances to smoking and chewing tobacco respectively when they belong to 
households where the household members listen to radio. Similarly, individuals have 0.93 times lower (SE: 0.033; $p$-value < 0.05) and 1.07 times higher (SE: 0.038; $p$-value < 0.1) chances of smoking tobacco and drinking alcohol respectively when they belong to households that watch TV.

Table- 6 shows the association between different modes of mass media exposure and tobacco and alcohol consumption in the second round of IHDS. The odds of smoking tobacco is 1.19 times higher (SE: 0.034; $p$-value < 0.01) and 0.90 times lower (SE: 0.027; $p$-value < 0.01 ) for individuals from households where the household members listen to radio and read newspaper respectively in case of models without unobserved heterogeneity. Similarly, the odds of chewing tobacco is 0.93 times lower (SE: 0.027; $p$-value < 0.01) and 1.17 times higher (SE: 0.036; p-value < 0.01) for individuals from households that listen to radio and read newspaper respectively for models without unobserved state-level heterogeneity. Again, the odds of drinking alcohol is 0.95 times lower (SE: 0.031; p-value < 0.1 ) for individuals from households that read newspaper. The pattern of association between the outcome and explanatory variables remains similar for models that control for unobserved state-level heterogeneity. Individuals have 1.11 times higher (SE: 0.035; $p$-value < 0.01), 0.91 times lower (SE: 0.029; p-value < 0.01) and 1.09 times higher (SE: 0.037; p-value $<0.01$ ) odds of smoking tobacco, chewing tobacco and drinking alcohol respectively when they belong to households where the household members listen to radio.

\section{Discussion}

Using both rounds of the India Human Development Survey; this study provides evidence of the association of mass media exposure with tobacco and alcohol consumption behaviour among the Indian population simultaneously accounting for unobserved heterogeneity at the state-level. In the first round of IHDS, listening to radio was associated with a higher likelihood of smoking tobacco, while lesser chance of smoking was seen among people with exposure to television. During the second round, this relationship had changed where exposure to both television and radio showed a higher likelihood of smoking tobacco. This change might be due to the ban on visual advertisement of smoking. However, different companies had also come up with strategies to influence the consumption behaviour among people. The association of media with the tobacco chewing behaviour were low as such habits are culturally acceptable and smokeless tobacco products are inexpensive and widely available across India (Gupta, 2003; Sauvaget et al., 2008). The findings of the current study contradicted those of (Viswanath et al., 2010) where positive association between television and chewing tobacco was seen. In the current study, reading newspapers was positively associated with alcohol consumption behaviour in the first round, while there is no association of mass media exposure with alcohol consumption in the second round. Generally, the newspaper does not carry contents that promote these kinds of consumption; however, it is likely to carry content that limit the consumption behaviour among people. Additionally, it is likely that the readership of newspapers consists of educated people who are conscious of the harmful effect of tobacco and alcohol consumption and inhibit themselves from such risky behaviour. Similar results were also seen in the study of Viswanath et al.,(2010). 
Because of analysing data of the overall population, this study noticed patterns in the consumption behaviour among different age groups. Results related to the control variables were not shown in the tables of multivariable analysis. However, this study found that people in the age group of 20-69 years were highly likely to consume tobacco or alcohol compared to people in the younger ages in both rounds of IHDS. This might be due to influence of social relations in these ages where consumption behaviour among people in the same social groups influences others to pick up the similar behaviour. The current study also found that in both rounds of IHDS the female population were more likely to consume smokeless tobacco in comparison to their male counterparts and these findings were similar to the study by Gupta, P. C. (2003). The study also found that people with an above primary level of education are less likely to smoke tobacco and consume alcohol in comparison to individuals who had no formal schooling in both rounds of IHDS. Additional the study also found that, people living in the urban areas were less prone to consume alcohol or smoke tobacco compared to their rural counterparts in the first round. However, during the second round a higher likelihood of tobacco and alcohol consumption was seen among people living in urban areas compared to people living in rural areas. Consumption of smoking tobacco and drinking alcohol was also highly prevalent among working people compared to people who were not involved in any occupation in both rounds of IHDS.

Different forms of media have the right to express their opinion in their own style along with the responsibility to educate, inform, and entertain people. Previous literature had brought forward both pros and cons of media exposure in households on the tobacco and alcohol consumption behaviour of individuals. The intention of this study is to provide evidence for both the supportive and resistive role of mass media exposure behind alcohol and tobacco consumption behaviour of the Indian population. A difference in association across various media sources in the current study highlighted the importance of understanding that the source through which information is received also matters. The study results show that visual media (that is television) is a promoting agent of tobacco and alcohol consumption behaviour in the first round. However, during the second round visual media has emerged as an anti-agent of tobacco and alcohol consumption in India, which might be a result of anti-promotion campaigns of the Indian government. In contrast to this, print media had emerged as an anti-promotion agent of tobacco and alcohol consumption in both rounds of IHDS, which is because the readers of newspapers are more critical consumers than those exposed to visual media. Moreover, the content published in a newspaper is more health prone and oftentimes carry messages and stories about the harmful effect of these consumption behaviour. Across regions and states, the consumption pattern of tobacco and alcohol were found to be significantly varying in the current study.

(Singh \& Ladusingh (2014) in their study on India had shown that there is variation across the states in the pattern of consuming tobacco and alcohol. Chakrabarti et al. (2012) had shown in their study that every state has a different consumption pattern where in some states consumption is prominent by tradition whereas in some states generating materials for consumption is the livelihood of the people. However, there is a lack of research evidence that shows the association of media exposure with alcohol and tobacco consumption behaviour while simultaneously controlling for the variation in the risk of consumption at the state-level. The current study fills this research gap. Findings of this study have also 
brought attention to different media sources that act like a pro and anti-agent of tobacco and alcohol consumption. Visual media (television), which is most popular among the population, emerged as a pro agent while print media (that is newspaper) emerged as an anti-agent. One of the most important strengths of this study is that it included the whole population to see a pattern of consumption in contrast to other studies where population in specific age brackets were included. This result can also be useful in generalizing the situation in case of other developing nations. However, because of unavailability of information, the current study is unable to provide evidence for the role of the various types of content shown through each mode of mass media. Clearly, further research is necessary in this direction. Additionally, the emergence of the use of computers and mobile phones and role behind the promotion of tobacco and alcohol consumption behaviour could not be highlighted in this study. The current study determines association and not causality among the mass media exposure and tobacco or alcohol consumption behaviour among the Indian population. However, no evidence was found in the available literature about the causal effect of tobacco and alcohol consumption on the mass media exposure in people.

This study will help the concerned people and policymakers to understand the overall influence that different mass media sources exert on the chances of picking up risky lifestyle behaviours like smoking tobacco, chewing tobacco or drinking alcohol. Inspite of the presence of Cable Television Networks Amendment Act, which bans advertising of tobacco and alcohol products in India since 2000, mass media exposure emerged as an influential factor behind the tobacco and alcohol consumption behaviour in the Indian population. The tobacco and alcohol selling companies have found and used variety of methods for indirect advertising of their products. Proper execution of the anti-tobacco and anti-alcohol promotion campaigns of the government is necessary. Youngsters who usually have the curiosity of trying new things in their life should be made aware about the role of media messages as well as the pros and cons of indulging in tobacco and alcohol consumption. It is common knowledge that India is undergoing a demographic transition that would result in a higher proportion of working-age group population. These people will contribute towards the development of the country. Thus, it becomes a shared responsibility of policymakers and people to ensure that the population does not suffer from avoidable causes of disability and mortality like tobacco and alcohol consumption.

\section{Declarations}

Funding Statement This research received no specific grant from any funding agency, commercial entity or not-for-profit organization.

Conflicts of Interest There is no conflict of interest in any of the authors.

Ethical Approval IHDS datasets used for analysis are publicly available with no information that discloses the identity of the respondents. Thus, there was no need for prior permission and ethical approval for using the datasets. The data can be obtained from the IHDS website (Desai et al., 2008; Desai \& Vanneman, 2015). 


\section{References}

1. Anand, A., \& Roy, N. (2016). Prevalence and determinants of co-use of alcohol and tobacco among men in working age group (18-59 years) in India. Epidemiology, Biostatistics and Public Health, 13(1).

2. Anderson, P., De Bruijn, A., Angus, K., Gordon, R., \& Hastings, G. (2009). Impact of alcohol advertising and media exposure on adolescent alcohol use: a systematic review of longitudinal studies. Alcohol and Alcoholism, 44(3), 229-243.

3. Cameron, A. C. ., \& Trivedi, P. K. (2005). Microeconometrics: Methods and Applications.

4. Chakrabarti, A., Rai, B., \& Panda, S. (2012). Producer, sellers and drinkers-studies of noncommercial alcohol in nine countries. Int Cent Alcohol Policies Monogr Ser, 33-38.

5. Chudley, A. E., Conry, J., Cook, J. L., Loock, C., Rosales, T., \& LeBlanc, N. (2005). Public Health Agency of Canada's National Advisory Committee on fetal alcohol spectrum disorder. Fetal alcohol spectrum disorder: Canadian guidelines for diagnosis. Cmaj, 172(5 Suppl), S1-S21.

6. Connery, H. S., Albright, B. B., \& Rodolico, J. M. (2014a). Adolescent substance use and unplanned pregnancy: strategies for risk reduction. Obstetrics and Gynecology Clinics, 41(2), 191-203.

7. Connery, H. S., Albright, B. B., \& Rodolico, J. M. (2014b). Adolescent substance use and unplanned pregnancy: Strategies for risk reduction. Obstetrics and Gynecology Clinics of North America, 41(2), 191-203. https://doi.org/10.1016/j.ogc.2014.02.011

8. Desai, S., Dubey, A., Joshi, B. L., Sen, M., Sharif, A., \& Vanneman, R. (2010). India Human Development Survey Users' Guide Release 03. Retrieved June 23, 2020, from University of Maryland and National Council of Applied Economic Research, New Delhi website: https://www.icpsr.umich.edu/web/pages/DSDR/idhs-data-guide.html

9. Desai, S., \& Vanneman, R. (2015). India Human Development Survey-II (IHDS-II), 2011-12: Version 6 [Data set]. Retrieved June 23, 2020, from Inter-University Consortium for Political and Social Research website: https://www.icpsr.umich.edu/web/DSDR/studies/36151/versions/V6

10. Desai, S., Vanneman, R., \& National Council Of Applied Economic Research, N. D. (2008). India Human Development Survey (IHDS), 2005: Version 12 [Data set]. Retrieved June 23, 2020, from InterUniversity Consortium for Political and Social Research. website:

https://www.icpsr.umich.edu/web/DSDR/studies/22626

11. Factsheet, I. (n.d.). National family health survey (NFHS-4) 2015-16 [Internet]. Mumbai: International Institute for Population Sciences (IIPS); 2017.[cited 2018 Sep 07]. India. Pdf.[Google Scholar].

12. Goldstein, H. (2011). Multilevel statistical models (Vol. 922). John Wiley \& Sons.

13. Gupta, A. K., Ladusingh, L., \& Borkotoky, K. (2016). Spatial clustering and risk factors of infant mortality : district-level assessment of high- focus states in India. Genus. https://doi.org/10.1186/s41118-016-0008-9

14. Gupta, P. C. (2003). Ray CS smokeless tobacco in India and Southeast Asia. Respirology, 8, 419-431. 
15. Hammer, J. H., Parent, M. C., Spiker, D. A., \& World Health Organization. (2018). Global status report on alcohol and health 2018. In Global status report on alcohol(Vol. 65). https://doi.org/10.1037/cou0000248

16. Holak, S. L., \& Reddy, S. K. (1986). Effects of a Television and Radio Advertising Ban: A Study of the Cigarette Industry. Journal of Marketing, 50(4), 219. https://doi.org/10.2307/1251297

17. Institute, N. C. (2008). The role of the media in promoting and reducing tobacco use. Tobacco Control Monograph No. 19. US Department of Health and Human Services, National Institutes of Health ....

18. John, R. M., Sung, H. Y., \& Max, W. (2009). Economic cost of tobacco use in India, 2004. Tobacco Control, 18(2), 138-143.

19. Mathivanan, J., Vigneshwaran, K., \& Sinu, E. (2015). Do Movies Influence Smoking Among Adolescents? International Journal of Health Sciences and Research, 5(4), 1-13.

20. McCool, J., Freeman, B., \& Tanielu, H. (2014). Perceived social and media influences on tobacco use among Samoan youth. BMC Public Health, 14(1), 1-8.

21. Merlo, J., Chaix, B., Ohlsson, H., Beckman, A., Johnell, K., \& Hjerpe, P. (2006). logistic regression to investigate contextual phenomena. 290-297. https://doi.org/10.1136/jech.2004.029454

22. Merlo, J., Chaix, B., Ohlsson, H., Beckman, A., Johnell, K., Hjerpe, P., ... Larsen, K. (2006). A brief conceptual tutorial of multilevel analysis in social epidemiology: using measures of clustering in multilevel logistic regression to investigate contextual phenomena. Journal of Epidemiology \& Community Health, 60(4), 290-297.

23. Ministry of Health and Family Welfare Government of India. (2017). Global adult tobacco survey, India 2016-17. February-2014, 360. Retrieved from https://www.who.int/tobacco/surveillance/survey/gats/GATS_India_201617_FactSheet.pdf\%0ATata Institute of Social Sciences (TISS), Mumbai and Ministry of Health and Family Welfare, Government of India. Global Adult Tobacco Survey GATS 2 India 2016-17.\%0AIS

24. Mohan, P., Lando, H. A., \& Panneer, S. (2018). Assessment of tobacco consumption and control in India. Indian Journal of Clinical Medicine, 9, 1179916118759289.

25. Nunez-Smith, M., Wolf, E., Huang, H. M., Chen, P. G., Lee, L., Emanuel, E. J., \& Gross, C. P. (2010). Media exposure and tobacco, illicit drugs, and alcohol use among children and adolescents: a systematic review. Substance Abuse, 31(3), 174-192.

26. Sauvaget, C., Ramadas, K., Thara, S., Thomas, G., \& Sankaranarayanan, R. (2008). Tobacco chewing in India. International Journal of Epidemiology, 37(6), 1242-1245.

27. Schoeps, A., Peterson, E. R., Mia, Y., Waldie, K. E., Underwood, L., D’Souza, S., \& Morton, S. M. B. (2018). Prenatal alcohol consumption and infant and child behavior: Evidence from the Growing Up in New Zealand Cohort. Early Human Development, 123, 22-29.

28. Singh, A., \& Ladusingh, L. (2014). Prevalence and determinants of tobacco use in India: evidence from recent Global Adult Tobacco Survey data. PloS One, 9(12), e114073.

29. Sinha, D. N., Palipudi, K. M., Rolle, I., Asma, S., \& Rinchen, S. (2011). Tobacco use among youth and adults in member countries of South-East Asia region: review of findings from surveys under the 
Global Tobacco Surveillance System. Indian Journal of Public Health, 55(3), 169.

30. Snijders, T. A. B., \& Bosker, R. J. (2011). Multilevel analysis: An introduction to basic and advanced multilevel modeling. Retrieved June 23, 2020, from Sage website: https://www.stats.ox.ac.uk/ snijders/mlbook.htm

31. StataCorp, L. P. (2014). Stata 13. College Station: StataCorp LP.

32. Thankappan, K. R., \& Thresia, C. U. (2007). Tobacco use \& social status in Kerala. Indian Journal of Medical Research, 126(4), 300.

33. Viswanath, K., Ackerson, L. K., Sorensen, G., \& Gupta, P. C. (2010). Movies and TV influence tobacco use in India: findings from a national survey. PLoS One, 5(6), e11365.

34. Wakefield, M., Flay, B., Nichter, M., \& Giovino, G. (2003). Role of the media in influencing trajectories of youth smoking. Addiction, 98, 79-103.

35. Young, B., Lewis, S., Katikireddi, S. V., Bauld, L., Stead, M., Angus, K., ... Hinds, K. (2018). Effectiveness of mass media campaigns to reduce alcohol consumption and harm: a systematic review. Alcohol and Alcoholism, 53(3), 302-316.

\section{Tables}

Table 1: Distribution of individuals in the first round of IHDS by relevant demographic, socioeconomic and state-level characteristics 


\begin{tabular}{|c|c|c|c|c|c|c|c|c|}
\hline \multirow[t]{2}{*}{ Variables } & \multicolumn{2}{|c|}{$\begin{array}{l}\text { Total } \\
\text { Population }\end{array}$} & \multicolumn{2}{|c|}{$\begin{array}{l}\text { Smokes } \\
\text { Tobacco }\end{array}$} & \multicolumn{2}{|c|}{$\begin{array}{l}\text { Chews } \\
\text { Tobacco }\end{array}$} & \multicolumn{2}{|c|}{$\begin{array}{l}\text { Drinks } \\
\text { Alcohol }\end{array}$} \\
\hline & $\mathbf{N}$ & $\%$ & $\mathbf{N}$ & $\%$ & $\mathbf{N}$ & $\%$ & $\mathbf{N}$ & $\%$ \\
\hline \multicolumn{9}{|c|}{$\begin{array}{l}\text { Household } \\
\text { members listen to } \\
\text { radio }\end{array}$} \\
\hline No & 16930 & 49.2 & 9710 & 48.8 & 9761 & 47.7 & 5244 & 50.8 \\
\hline Yes & 16186 & 50.8 & 9571 & 51.2 & 9699 & 52.3 & 5048 & 49.2 \\
\hline \multicolumn{9}{|c|}{$\begin{array}{l}\text { Household } \\
\text { members read } \\
\text { newspaper }\end{array}$} \\
\hline No & 18576 & 57.4 & 10961 & 59.4 & 11133 & 57.0 & 5654 & 57.0 \\
\hline Yes & 14540 & 42.6 & 8320 & 40.6 & 8327 & 43.0 & 4638 & 43.0 \\
\hline \multicolumn{9}{|c|}{$\begin{array}{l}\text { Household } \\
\text { members watch } \\
\text { TV }\end{array}$} \\
\hline No & 10126 & 31.9 & 5968 & 33.4 & 6250 & 32.7 & 2967 & 29.9 \\
\hline Yes & 22990 & 68.1 & 13313 & 66.6 & 13210 & 67.3 & 7325 & 70.1 \\
\hline \multicolumn{9}{|c|}{$\begin{array}{l}\text { Age-grouped by } 10 \\
\text { years }\end{array}$} \\
\hline $0-9$ & 43 & 0.1 & 21 & 0.1 & 30 & 0.2 & 12 & 0.2 \\
\hline 10-19 & 610 & 2.0 & 227 & 1.3 & 490 & 2.7 & 110 & 1.4 \\
\hline $20-29$ & 4889 & 15.3 & 2551 & 14.0 & 3157 & 16.3 & 1564 & 16.1 \\
\hline $30-39$ & 8078 & 23.8 & 4633 & 23.8 & 4729 & 23.3 & 2906 & 28.1 \\
\hline $40-49$ & 7972 & 24.2 & 4958 & 25.6 & 4414 & 23.1 & 2726 & 26.6 \\
\hline $50-59$ & 5777 & 17.4 & 3611 & 18.7 & 3237 & 16.5 & 1711 & 16.1 \\
\hline $60-69$ & 3745 & 11.6 & 2164 & 11.2 & 2207 & 12.0 & 887 & 8.2 \\
\hline 70-79 & 1579 & 4.4 & 872 & 4.0 & 946 & 4.5 & 318 & 2.5 \\
\hline $80+$ & 423 & 1.3 & 244 & 1.2 & 250 & 1.3 & 58 & 0.7 \\
\hline \multicolumn{9}{|c|}{ Sex of individual } \\
\hline Male & 27609 & 83.7 & 18280 & 94.5 & 14770 & 78.0 & 9712 & 94.0 \\
\hline Female & 5507 & 16.3 & 1001 & 5.5 & 4690 & 22.0 & 580 & 6.0 \\
\hline
\end{tabular}




\begin{tabular}{|c|c|c|c|c|c|c|c|c|}
\hline $\begin{array}{l}\text { No Formal } \\
\text { Schooling }\end{array}$ & 13555 & 42.6 & 7525 & 41.3 & 8307 & 43.2 & 3937 & 41.7 \\
\hline Standard 1-5 & 6715 & 20.9 & 4058 & 21.5 & 4038 & 21.0 & 2115 & 21.9 \\
\hline Standard 6-10 & 9825 & 28.1 & 5983 & 28.9 & 5430 & 27.5 & 3280 & 28.2 \\
\hline Standard >10 & 3021 & 8.4 & 1715 & 8.4 & 1685 & 8.3 & 960 & 8.2 \\
\hline \multicolumn{9}{|c|}{$\begin{array}{l}\text { Current working } \\
\text { status of individual }\end{array}$} \\
\hline Not working & 15373 & 46.3 & 8282 & 43.2 & 9570 & 49.2 & 3607 & 33.3 \\
\hline Working & 17743 & 53.7 & 10999 & 56.8 & 9890 & 50.8 & 6685 & 66.7 \\
\hline \multicolumn{9}{|c|}{$\begin{array}{l}\text { Current marital } \\
\text { status of individual }\end{array}$} \\
\hline Married & 28455 & 85.3 & 17124 & 88.0 & 16250 & 83.0 & 9271 & 89.5 \\
\hline Unmarried & 4661 & 14.7 & 2157 & 12.0 & 3210 & 17.0 & 1021 & 10.5 \\
\hline \multicolumn{9}{|c|}{$\begin{array}{l}\text { Highest } \\
\text { educational level } \\
\text { of } \\
\text { male adult (21+ } \\
\text { years) }\end{array}$} \\
\hline $\begin{array}{l}\text { No Formal } \\
\text { Schooling }\end{array}$ & 8992 & 28.7 & 5270 & 29.8 & 5410 & 28.2 & 2955 & 31.7 \\
\hline Standard 1-5 & 5970 & 18.8 & 3442 & 18.8 & 3683 & 19.0 & 1892 & 20.3 \\
\hline Standard 6-10 & 8669 & 26.4 & 5115 & 26.2 & 5101 & 26.8 & 2589 & 24.3 \\
\hline Standard >10 & 9485 & 26.0 & 5454 & 25.2 & 5266 & 25.9 & 2856 & 23.7 \\
\hline \multicolumn{9}{|c|}{$\begin{array}{l}\text { Highest } \\
\text { educational level } \\
\text { of } \\
\text { female adult ( } 21+ \\
\text { years) }\end{array}$} \\
\hline $\begin{array}{l}\text { No Formal } \\
\text { Schooling }\end{array}$ & 17784 & 56.5 & 10659 & 58.2 & 10666 & 56.8 & 5535 & 59.1 \\
\hline Standard 1-5 & 5034 & 15.1 & 2814 & 14.5 & 3051 & 15.3 & 1524 & 13.7 \\
\hline Standard 6-10 & 5624 & 16.4 & 3117 & 15.7 & 3320 & 16.7 & 1701 & 15.2 \\
\hline Standard >10 & 4674 & 11.9 & 2691 & 11.7 & 2423 & 11.2 & 1532 & 12.0 \\
\hline \multicolumn{9}{|c|}{$\begin{array}{l}\text { Wealth quintile of } \\
\text { household }\end{array}$} \\
\hline Poorest & 7460 & 26.3 & 3752 & 24.6 & 5362 & 30.3 & 2269 & 26.7 \\
\hline
\end{tabular}




\begin{tabular}{|c|c|c|c|c|c|c|c|c|}
\hline Poor & 7147 & 24.1 & 4224 & 25.0 & 4518 & 25.0 & 2053 & 22.5 \\
\hline Medium & 6958 & 20.5 & 4329 & 21.2 & 3781 & 18.8 & 2196 & 21.8 \\
\hline Rich & 6547 & 17.5 & 4014 & 17.6 & 3421 & 16.0 & 2103 & 17.2 \\
\hline Richest & 5004 & 11.5 & 2962 & 11.5 & 2378 & 9.9 & 1671 & 11.7 \\
\hline \multicolumn{9}{|c|}{$\begin{array}{l}\text { Caste of } \\
\text { household head }\end{array}$} \\
\hline OBC & 12811 & 40.4 & 7306 & 39.5 & 7885 & 41.8 & 3398 & 36.5 \\
\hline SC & 7521 & 24.4 & 4612 & 25.8 & 4216 & 23.5 & 2780 & 29.6 \\
\hline ST & 3983 & 10.4 & 1944 & 8.8 & 2910 & 11.9 & 1846 & 16.6 \\
\hline Others & 8801 & 24.8 & 5419 & 25.9 & 4449 & 22.8 & 2268 & 17.3 \\
\hline \multicolumn{9}{|c|}{$\begin{array}{l}\text { Religion of } \\
\text { household head }\end{array}$} \\
\hline Hindu & 27046 & 83.4 & 15619 & 81.9 & 16001 & 84.4 & 8584 & 86.6 \\
\hline Muslim & 3657 & 11.4 & 2469 & 13.6 & 1978 & 10.3 & 395 & 3.9 \\
\hline Others & 2413 & 5.2 & 1193 & 4.5 & 1481 & 5.2 & 1313 & 9.5 \\
\hline \multicolumn{9}{|c|}{ Place of residence } \\
\hline Rural & 24641 & 80.6 & 14316 & 80.7 & 14694 & 82.2 & 7686 & 80.5 \\
\hline Urban & 8475 & 19.4 & 4965 & 19.3 & 4766 & 17.8 & 2606 & 19.5 \\
\hline \multicolumn{9}{|l|}{ Region } \\
\hline Central & 7663 & 26.6 & 4280 & 26.4 & 5490 & 31.5 & 1658 & 17.9 \\
\hline Northern & 6522 & 11.0 & 5282 & 15.8 & 1568 & 4.7 & 2316 & 10.6 \\
\hline Southern & 5683 & 16.4 & 3574 & 18.0 & 2270 & 9.5 & 2294 & 26.8 \\
\hline Western & 4302 & 14.9 & 1476 & 8.8 & 3351 & 18.5 & 1122 & 12.2 \\
\hline Eastern & 6572 & 25.8 & 3028 & 24.1 & 5077 & 30.3 & 2069 & 27.1 \\
\hline North-eastern & 2374 & 5.3 & 1641 & 6.9 & 1704 & 5.6 & 833 & 5.4 \\
\hline Total & 33116 & 100 & 19281 & 100 & 19460 & 100 & 10292 & 100 \\
\hline
\end{tabular}

Table 2: Distribution of individuals in the second round of IHDS by relevant demographic, socioeconomic and state-level characteristics 


\begin{tabular}{|c|c|c|c|c|c|c|c|c|}
\hline \multirow[t]{2}{*}{ Variables } & \multicolumn{2}{|c|}{$\begin{array}{l}\text { Total } \\
\text { Population }\end{array}$} & \multicolumn{2}{|c|}{$\begin{array}{l}\text { Smokes } \\
\text { Tobacco }\end{array}$} & \multicolumn{2}{|c|}{$\begin{array}{l}\text { Chews } \\
\text { Tobacco }\end{array}$} & \multicolumn{2}{|c|}{$\begin{array}{l}\text { Drinks } \\
\text { Alcohol }\end{array}$} \\
\hline & $\mathbf{N}$ & $\%$ & $\mathbf{N}$ & $\%$ & $\mathbf{N}$ & $\%$ & $\mathbf{N}$ & $\%$ \\
\hline \multicolumn{9}{|c|}{$\begin{array}{l}\text { Household } \\
\text { members listen to } \\
\text { radio }\end{array}$} \\
\hline No & 24172 & 67.0 & 10321 & 67.4 & 14841 & 65.0 & 7204 & 70.1 \\
\hline Yes & 9918 & 33.0 & 4367 & 32.6 & 6244 & 35.0 & 2673 & 29.9 \\
\hline \multicolumn{9}{|c|}{$\begin{array}{l}\text { Household } \\
\text { members read } \\
\text { newspaper }\end{array}$} \\
\hline No & 16584 & 50.4 & 7330 & 52.6 & 10676 & 51.4 & 4811 & 52.5 \\
\hline Yes & 17506 & 49.6 & 7358 & 47.4 & 10409 & 48.6 & 5066 & 47.5 \\
\hline \multicolumn{9}{|c|}{$\begin{array}{l}\text { Household } \\
\text { members watch TV }\end{array}$} \\
\hline No & 6398 & 21.2 & 2874 & 21.2 & 4298 & 22.9 & 1813 & 22.6 \\
\hline Yes & 27692 & 78.8 & 11814 & 78.8 & 16787 & 77.1 & 8064 & 77.4 \\
\hline \multicolumn{9}{|c|}{$\begin{array}{l}\text { Age-grouped by } 10 \\
\text { years }\end{array}$} \\
\hline $0-9$ & 67 & 0.2 & 5 & 0.0 & 29 & 0.1 & 6 & 0.0 \\
\hline $10-19$ & 717 & 2.3 & 110 & 0.8 & 541 & 2.6 & 76 & 0.8 \\
\hline $20-29$ & 4530 & 13.6 & 1375 & 9.5 & 3329 & 15.6 & 1222 & 12.9 \\
\hline $30-39$ & 7205 & 20.2 & 2927 & 19.3 & 4679 & 21.1 & 2442 & 24.4 \\
\hline $40-49$ & 8087 & 23.4 & 3810 & 26.0 & 4717 & 22.0 & 2673 & 27.0 \\
\hline 50-59 & 6402 & 18.8 & 3163 & 21.8 & 3602 & 17.2 & 1866 & 18.6 \\
\hline $60-69$ & 4515 & 13.8 & 2130 & 14.7 & 2627 & 13.6 & 1117 & 11.6 \\
\hline 70-79 & 1940 & 5.7 & 884 & 5.8 & 1168 & 5.8 & 362 & 3.7 \\
\hline $80+$ & 627 & 2.0 & 284 & 2.2 & 393 & 1.9 & 113 & 1.0 \\
\hline \multicolumn{9}{|c|}{ Sex of individual } \\
\hline Male & 28306 & 83.1 & 13851 & 93.7 & 16413 & 79.3 & 9501 & 96.0 \\
\hline Female & 5784 & 16.9 & 837 & 6.3 & 4672 & 20.7 & 376 & 4.0 \\
\hline $\begin{array}{l}\text { Level of ec } \\
\text { of individu }\end{array}$ & & & & & & & & \\
\hline
\end{tabular}




\begin{tabular}{|c|c|c|c|c|c|c|c|c|}
\hline $\begin{array}{l}\text { No Formal } \\
\text { Schooling }\end{array}$ & 12542 & 38.5 & 5574 & 40.0 & 8050 & 39.5 & 3329 & 37.3 \\
\hline Standard 1-5 & 6947 & 19.8 & 3246 & 22.0 & 4289 & 19.2 & 2066 & 20.5 \\
\hline Standard 6-10 & 10959 & 31.1 & 4594 & 29.9 & 6594 & 30.7 & 3445 & 32.6 \\
\hline Standard $>10$ & 3642 & 10.6 & 1274 & 8.1 & 2152 & 10.5 & 1037 & 9.5 \\
\hline \multicolumn{9}{|l|}{$\begin{array}{l}\text { Current working } \\
\text { status }\end{array}$} \\
\hline Not working & 7191 & 21.6 & 2108 & 14.5 & 4853 & 23.1 & 1010 & 9.9 \\
\hline Working & 26899 & 78.4 & 12580 & 85.5 & 16232 & 76.9 & 8867 & 90.1 \\
\hline \multicolumn{9}{|l|}{$\begin{array}{l}\text { Current marital } \\
\text { status }\end{array}$} \\
\hline Married & 28335 & 82.5 & 12852 & 87.3 & 17115 & 80.9 & 8784 & 88.7 \\
\hline Unmarried & 5755 & 17.5 & 1836 & 12.7 & 3970 & 19.1 & 1093 & 11.3 \\
\hline \multicolumn{9}{|c|}{$\begin{array}{l}\text { Highest educational } \\
\text { level of } \\
\text { male adult }(21+ \\
\text { years) }\end{array}$} \\
\hline $\begin{array}{l}\text { No Formal } \\
\text { Schooling }\end{array}$ & 7784 & 25.1 & 3677 & 28.2 & 5002 & 25.5 & 2286 & 26.6 \\
\hline Standard 1-5 & 5768 & 17.0 & 2587 & 18.4 & 3696 & 16.8 & 1701 & 17.6 \\
\hline Standard 6-10 & 13064 & 36.8 & 5552 & 35.7 & 8070 & 37.4 & 3944 & 38.1 \\
\hline Standard $>10$ & 7474 & 21.0 & 2872 & 17.7 & 4317 & 20.4 & 1946 & 17.7 \\
\hline \multicolumn{9}{|c|}{$\begin{array}{l}\text { Highest educational } \\
\text { level of } \\
\text { female adult ( } 21+ \\
\text { years) }\end{array}$} \\
\hline $\begin{array}{l}\text { No Formal } \\
\text { Schooling }\end{array}$ & 15266 & 47.8 & 7189 & 51.9 & 9823 & 49.2 & 4497 & 50.3 \\
\hline Standard 1-5 & 5323 & 15.2 & 2256 & 15.3 & 3378 & 15.3 & 1486 & 14.5 \\
\hline Standard 6-10 & 9248 & 25.5 & 3597 & 23.1 & 5611 & 25.0 & 2631 & 24.4 \\
\hline Standard >10 & 4253 & 11.5 & 1646 & 9.7 & 2273 & 10.5 & 1263 & 10.8 \\
\hline \multicolumn{9}{|c|}{$\begin{array}{l}\text { Wealth quintile of } \\
\text { household }\end{array}$} \\
\hline Poorest & 7463 & 27.7 & 3036 & 27.1 & 5584 & 32.1 & 2074 & 27.3 \\
\hline Poor & 7933 & 23.5 & 3473 & 24.8 & 5374 & 24.8 & 2105 & 22.2 \\
\hline Medium & 7399 & 20.1 & 3284 & 20.0 & 4442 & 19.2 & 2100 & 20.7 \\
\hline
\end{tabular}




\begin{tabular}{|c|c|c|c|c|c|c|c|c|}
\hline Rich & 6158 & 16.2 & 2749 & 16.7 & 3267 & 13.7 & 1903 & 17.0 \\
\hline Richest & 5137 & 12.5 & 2146 & 11.4 & 2418 & 10.3 & 1695 & 12.9 \\
\hline \multicolumn{9}{|c|}{$\begin{array}{l}\text { Caste of household } \\
\text { head }\end{array}$} \\
\hline OBC & 13649 & 41.1 & 5635 & 39.5 & 8866 & 42.5 & 3412 & 37.7 \\
\hline SC & 8005 & 24.4 & 3876 & 28.4 & 4597 & 22.6 & 2840 & 28.8 \\
\hline ST & 3921 & 11.1 & 1362 & 8.5 & 2828 & 12.6 & 1629 & 17.4 \\
\hline Others & 8515 & 23.4 & 3815 & 23.7 & 4794 & 22.3 & 1996 & 16.1 \\
\hline \multicolumn{9}{|c|}{$\begin{array}{l}\text { Religion of } \\
\text { household head }\end{array}$} \\
\hline Hindu & 28235 & 83.1 & 12103 & 83.8 & 17745 & 83.9 & 8666 & 88.2 \\
\hline Muslim & 3980 & 11.5 & 1933 & 12.8 & 2405 & 11.1 & 267 & 2.9 \\
\hline Others & 1875 & 5.4 & 652 & 3.4 & 935 & 5.0 & 944 & 8.9 \\
\hline \multicolumn{9}{|c|}{ Place of residence } \\
\hline Rural & 24795 & 75.6 & 10998 & 77.1 & 15678 & 77.6 & 7100 & 74.9 \\
\hline Urban & 9295 & 24.4 & 3690 & 22.9 & 5407 & 22.4 & 2777 & 25.1 \\
\hline \multicolumn{9}{|l|}{ Region } \\
\hline Central & 9615 & 32.0 & 3919 & 31.7 & 7346 & 38.3 & 2301 & 25.4 \\
\hline Northern & 6925 & 11.6 & 4397 & 17.4 & 2431 & 7.2 & 2619 & 13.3 \\
\hline Southern & 5566 & 15.5 & 2629 & 18.5 & 2532 & 9.7 & 2309 & 25.4 \\
\hline Western & 4186 & 13.4 & 866 & 6.8 & 3296 & 16.2 & 678 & 7.9 \\
\hline Eastern & 6206 & 23.8 & 2012 & 20.9 & 4606 & 25.8 & 1488 & 24.0 \\
\hline North-eastern & 1592 & 3.7 & 865 & 4.7 & 874 & 2.7 & 482 & 3.9 \\
\hline Total & 34090 & 100 & 14688 & 100 & 21085 & 100 & 9877 & 100 \\
\hline
\end{tabular}

Table 3: Indicators of state-level heterogeneity and clustering in the sample of the first round of IHDS using a random effect logit model 


\begin{tabular}{|lllllll|}
\hline Measures & \multicolumn{2}{l}{ Smokes tobacco } & \multicolumn{2}{l|}{ Chews tobacco } & \multicolumn{2}{l|}{ Drinks alcohol } \\
\cline { 2 - 8 } & $\begin{array}{l}\text { Null } \\
\text { model }\end{array}$ & $\begin{array}{l}\text { Full } \\
\text { model }\end{array}$ & $\begin{array}{l}\text { Null } \\
\text { model }\end{array}$ & $\begin{array}{l}\text { Full } \\
\text { model }\end{array}$ & $\begin{array}{l}\text { Null } \\
\text { model }\end{array}$ & $\begin{array}{l}\text { Full } \\
\text { model }\end{array}$ \\
\hline Variance & 1.149 & 0.685 & 2.531 & 0.769 & 1.456 & 1.249 \\
\hline $\begin{array}{l}\text { Intra-class Correlation } \\
\text { Coefficient (ICC) }\end{array}$ & 0.259 & 0.172 & 0.435 & 0.189 & 0.307 & 0.275 \\
\hline Median Odds Ratio (MOR) & 2.78 & 2.20 & 4.56 & 2.31 & 3.16 & 2.90 \\
\hline No of persons & 33,116 & 33,116 & 33,116 & 33,116 & 33,116 & 33,116 \\
\hline No of states & 33 & 33 & 33 & 33 & 33 & 33 \\
\hline
\end{tabular}

Note - (1) Null model denotes an empty model without any covariates (2) Full model is a model with all the covariates

Table 4: Indicators of state-level heterogeneity and clustering in the sample of the second round of IHDS using the random effect logit model

\begin{tabular}{|lllllll|}
\hline Measures & \multicolumn{2}{l}{ Smokes tobacco } & \multicolumn{2}{l|}{ Chews tobacco } & \multicolumn{2}{l|}{ Drinks alcohol } \\
\cline { 2 - 8 } & $\begin{array}{l}\text { Null } \\
\text { model }\end{array}$ & $\begin{array}{l}\text { Full } \\
\text { model }\end{array}$ & $\begin{array}{l}\text { Null } \\
\text { model }\end{array}$ & $\begin{array}{l}\text { Full } \\
\text { model }\end{array}$ & $\begin{array}{l}\text { Null } \\
\text { model }\end{array}$ & $\begin{array}{l}\text { Full } \\
\text { model }\end{array}$ \\
\hline Variance & 1.141 & 0.743 & 1.808 & 0.909 & 1.224 & 1.339 \\
\hline $\begin{array}{l}\text { Intraclass Correlation } \\
\text { Coefficient (ICC) }\end{array}$ & 0.257 & 0.184 & 0.355 & 0.217 & 0.271 & 0.289 \\
\hline Median Odds Ratio (MOR) & 2.77 & 2.28 & 3.61 & 2.48 & 2.87 & 3.02 \\
\hline No of persons & 34,090 & 34,090 & 34,090 & 34,090 & 34,090 & 34,090 \\
\hline No of states & 33 & 33 & 33 & 33 & 33 & 33 \\
\hline
\end{tabular}

Note - (1) Null model denotes an empty model without any covariates (2) Full model is a model with all the covariates

Table 5: Results of multivariable analysis showing the association (odds ratio) between media exposure and tobacco and alcohol consumption in the first round of IHDS 


\begin{tabular}{|c|c|c|c|c|c|c|}
\hline \multirow[t]{2}{*}{ Variables } & \multicolumn{3}{|c|}{$\begin{array}{l}\text { Model without unobserved } \\
\text { heterogeneity }\end{array}$} & \multicolumn{3}{|c|}{$\begin{array}{l}\text { Model with unobserved } \\
\text { heterogeneity }\end{array}$} \\
\hline & $\begin{array}{l}\text { Smokes } \\
\text { tobacco }\end{array}$ & $\begin{array}{l}\text { Chews } \\
\text { tobacco }\end{array}$ & $\begin{array}{l}\text { Drinks } \\
\text { alcohol }\end{array}$ & $\begin{array}{l}\text { Smokes } \\
\text { tobacco }\end{array}$ & $\begin{array}{l}\text { Chews } \\
\text { tobacco }\end{array}$ & $\begin{array}{l}\text { Drinks } \\
\text { alcohol }\end{array}$ \\
\hline \multicolumn{7}{|l|}{$\begin{array}{l}\text { Household } \\
\text { members } \\
\text { listen to radio }\end{array}$} \\
\hline No ${ }^{\circledR}$ & 1.00 & 1.00 & 1.00 & 1.00 & 1.00 & 1.00 \\
\hline \multirow[t]{2}{*}{ Yes } & $1.07^{\star *}$ & $1.09 \star \star \star$ & 1.06 ** & $1.08^{\star \star \star}$ & $0.92^{\star \star \star}$ & 1.04 \\
\hline & $(0.029)$ & $(0.030)$ & $(0.029)$ & $(0.032)$ & $(0.028)$ & $(0.031)$ \\
\hline \multicolumn{7}{|l|}{$\begin{array}{l}\text { Household } \\
\text { members } \\
\text { read newspaper }\end{array}$} \\
\hline No ${ }^{\circledR}$ & 1.00 & 1.00 & 1.00 & 1.00 & 1.00 & 1.00 \\
\hline \multirow[t]{2}{*}{ Yes } & $0.91^{\star \star \star}$ & $1.18^{\star \star \star}$ & $1.10 \star \star \star$ & 1.00 & 1.00 & $1.12^{\star \star \star}$ \\
\hline & $(0.031)$ & $(0.041)$ & $(0.038)$ & $(0.037)$ & $(0.037)$ & $(0.041)$ \\
\hline \multicolumn{7}{|l|}{$\begin{array}{l}\text { Household } \\
\text { members } \\
\text { watch TV }\end{array}$} \\
\hline No ${ }^{\circledR}$ & 1.00 & 1.00 & 1.00 & 1.00 & 1.00 & 1.00 \\
\hline \multirow[t]{2}{*}{ Yes } & 0.96 & $0.93^{* *}$ & $1.13^{\star \star \star}$ & $0.93^{\star *}$ & 1.04 & $1.07 *$ \\
\hline & $(0.032)$ & $(0.031)$ & $(0.038)$ & $(0.033)$ & $(0.037)$ & $(0.038)$ \\
\hline No of persons & 33,116 & 33,116 & 33,116 & 33,116 & 33,116 & 33,116 \\
\hline No of states & & & & 33 & 33 & 33 \\
\hline
\end{tabular}

Note - (1) Standard error (SE) is given in brackets (2) Statistical significance is denoted by asterisks where *** p-value $<0.01,{ }^{*}$ p-value $<0.05$, * $p$-value $<0.1$ (3) $\circledast$ denotes reference category (4) While analysing we have controlled for different variables: age category; sex of individual; level of education; current working status; current marital status; highest educational level of an adult male aged more than 21 years in the household; highest educational level of an adult male aged more than 21 years in the household; wealth quintile of the household; caste of the household head; religion of the household head; place of residence; Region

Table 6: Results of multivariable analysis showing the association (odds ratio) between media exposure and tobacco and alcohol consumption in the second round of IHDS 


\begin{tabular}{|c|c|c|c|c|c|c|}
\hline \multirow[t]{2}{*}{ Variables } & \multicolumn{3}{|c|}{$\begin{array}{l}\text { Model without unobserved } \\
\text { heterogeneity }\end{array}$} & \multicolumn{3}{|c|}{$\begin{array}{l}\text { Model with unobserved } \\
\text { heterogeneity }\end{array}$} \\
\hline & $\begin{array}{l}\text { Smokes } \\
\text { tobacco }\end{array}$ & $\begin{array}{l}\text { Chews } \\
\text { tobacco }\end{array}$ & $\begin{array}{l}\text { Drinks } \\
\text { alcohol }\end{array}$ & $\begin{array}{l}\text { Smokes } \\
\text { tobacco }\end{array}$ & $\begin{array}{l}\text { Chews } \\
\text { tobacco }\end{array}$ & $\begin{array}{l}\text { Drinks } \\
\text { alcohol }\end{array}$ \\
\hline \multicolumn{7}{|l|}{$\begin{array}{l}\text { Household } \\
\text { members } \\
\text { listen to radio }\end{array}$} \\
\hline No ${ }^{\circledR}$ & 1.00 & 1.00 & 1.00 & 1.00 & 1.00 & 1.00 \\
\hline \multirow[t]{2}{*}{ Yes } & 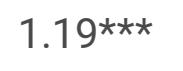 & $0.93^{\star \star *}$ & 0.98 & $1.11^{\star \star \star}$ & $0.91^{\star \star \star}$ & $1.09 \star \star \star$ \\
\hline & $(0.034)$ & $(0.027)$ & $(0.030)$ & (0.035) & $(0.029)$ & $(0.037)$ \\
\hline \multicolumn{7}{|c|}{$\begin{array}{l}\text { Household } \\
\text { members } \\
\text { read newspaper }\end{array}$} \\
\hline No ${ }^{\circledR}$ & 1.00 & 1.00 & 1.00 & 1.00 & 1.00 & 1.00 \\
\hline \multirow[t]{2}{*}{ Yes } & $0.90 * \star *$ & $1.17^{\star \star \star}$ & $0.95^{\star}$ & 0.95 & 0.99 & 1.00 \\
\hline & $(0.027)$ & $(0.036)$ & $(0.031)$ & $(0.031)$ & $(0.033)$ & $(0.035)$ \\
\hline \multicolumn{7}{|l|}{$\begin{array}{l}\text { Household } \\
\text { members } \\
\text { watch TV }\end{array}$} \\
\hline No ${ }^{\circledR}$ & 1.00 & 1.00 & 1.00 & 1.00 & 1.00 & 1.00 \\
\hline \multirow[t]{2}{*}{ Yes } & 1.05 & 0.96 & 1.02 & 1.02 & 1.04 & 0.97 \\
\hline & $(0.038)$ & $(0.036)$ & $(0.041)$ & $(0.039)$ & $(0.041)$ & $(0.041)$ \\
\hline No of persons & 34,090 & 34,090 & 34,090 & 34,090 & 34,090 & 34,090 \\
\hline No of states & & & & 33 & 33 & 33 \\
\hline
\end{tabular}

Note - (1) Standard error (SE) is given in brackets (2) Statistical significance is denoted by asterisks where $\star \star \star ~ p$-value $<0.01$, ** p-value $<0.05$, * p-value $<0.1$ (3) ${ }^{\circledR}$ denotes reference category (4) While analysing we have controlled for different variables: age category; sex of individual; level of education; current working status; current marital status; highest educational level of an adult male aged more than 21 years in the household; highest educational level of an adult male aged more than 21 years in the household; wealth quintile of the household; caste of the household head; religion of the household head; place of residence; Region 